\title{
Structure of the Western Tibetan Vortex inconsistent with a thermally-direct circulation
}

\author{
Xiao-Feng $\mathrm{Li}^{1,2,3}$. Jingjing $\mathrm{Yu}^{3} \cdot$ Shaofeng $\mathrm{Liu}^{1,2,3}$ - Jingzhi Wang ${ }^{1,2,3} \cdot$ Lei Wang $^{3}$
}

Received: 3 May 2021 / Accepted: 7 October 2021 / Published online: 23 November 2021

(C) The Author(s) 2021, corrected publication 2023

\begin{abstract}
The Western Tibetan Vortex (WTV) is a large-scale circulation pattern identified from year-to-year circulation variability, which was used to understand the causal mechanisms for slowdown of the glacier melting over the western Tibetan Plateau (TP). A recent argument has suggested the WTV is the set of wind field anomalies resulting from variability in near-surface air temperatures over the western TP (above $1500 \mathrm{~m}$ ), which, in turn, is likely driven by the surface net radiation. This study thereby evaluates the above putative thermal-direct mechanism. By conducting numerical sensitivity experiments using a global atmospheric circulation model, SAMIL, we find a WTV-like structure cannot be generated from a surface thermal forcing imposed on the western TP. A thermally-direct circulation generated by the surface or near surface heating is expect to cause upward motions and a baroclinic structure above it. In contrast, downward motions and a quasi-barotropic are observed in the vertical structure of the WTV. Besides, we find variability of the surface net radiation (sum of the surface shortwave and longwave net radiation) over the western TP can be traced back to the WTV variability based on ERA5 data. The anticyclonic (cyclonic) WTV reduces (increases) the cloudiness through the anomalous downward (upward) motions, causes more (less) input shortwave net radiation and thereby more (less) surface net radiations, resulting in the warmer (cooler) surface and near-surface air temperature over the western TP. The argument is constructive in encouraging examination of the radiative balance processes that complements previous studies.
\end{abstract}

Keywords Western Tibetan Plateau $\cdot$ Western Tibetan Vortex $\cdot$ Near-surface air temperature $\cdot$ Cloudiness $\cdot$ Surface net radiation $\cdot$ Thermally direct circulation $\cdot$ Generating mechanism

\section{Introduction}

A thermally-direct circulation is usually caused by a heating source in the lower- or mid-troposphere that warms up the air above/around it (e.g., Halley 1687; Ye and Wu 1998; Wu and Liu 2000; Holton 2004). The warm air then expands,

Xiao-Feng Li

lixf87@mail.sysu.edu.cn

$\triangle$ Jingjing Yu

yujingjing@sml-zhuhai.cn

1 Meteorology Department, School of Atmospheric Sciences, Sun Yat-sen University (Zhuhai Campus), Zhuhai 519082, Guangdong, China

2 Guangdong Province Key Laboratory for Climate Change and Natural Disaster Studies, Sun Yat-sen University, Guangzhou, China

3 Southern Marine Science and Engineering Guangdong Laboratory (Zhuhai), Zhuhai, China becomes less dense and then rises, resulting in a classic baroclinic structure, featuring as lower pressure in the midlower troposphere and at the near-surface level, but higher pressure in the upper troposphere (e.g., Holton 2004). In the mid- to high latitudes, where there is a stronger Coriolis force, these higher and lower pressure areas are usually associated with anti-cyclonic and cyclonic wind anomalies, respectively (e.g., Wu and Zhang 1998; Ye and Wu 1998). In reality, a thermally-direct circulation can involve more complex thermodynamic processes and features, such as condensing and latent heat release due to rising motions (e.g., Cornejo-Garrido and Stone 1977; Wu et al. 2007, 2015) and the stirring up of extra sub-vertical-circulations at its east and west edges due to vertical wind shears caused by its baroclinic structure (Wu et al. 2007, 2015). Its features may also vary under different background climates (e.g., Gill 1980; Jin and Hoskins 1995; Parker and Thorpe 1995). Thermally-direct circulations widely exist in Earth's atmosphere, the classic examples are the rising branches of 
the Hadley circulation (e.g., Halley 1687; Hadley 1735; Ferrel 1856; Thomson 1892) and the Walker circulation (e.g., Bjerknes 1969; Lau and Yang 2003). In short, the basic features of a thermally-direct circulation are: (1) anomalous rising motions and (2) a baroclinic structure (lower pressure at the ground surface and mid-lower troposphere, but higher pressure at the upper troposphere).

Forsythe et al. (2017) and Li et al. (2018) (hereafter collectively cited as FL1718) identified an atmospheric pattern or mode over the western TP in all four seasons and annual mean-termed the Karakoram/Western Tibetan Vortex (WTV, as shown in Fig. 1). Its intensity is measured by the Karakoram Zonal index (KZI). In the horizontal wind field, the WTV is shown as an evident anti-cyclonic (cyclonic) pattern with anomalous sinking (rising) motions at the center during its positive (negative) intensity phase (Fig. 1a, b). The WTV is identified in year-to-year circulation variability in all four seasons and annual mean (FL1718); the annual mean WTV on the mid-higher ( $250 \mathrm{hPa}$ level) and the mid-lower $\left(500 \mathrm{hPa}\right.$ level) troposphere extends from $\sim 50^{\circ} \mathrm{E}$ to $\sim 105^{\circ} \mathrm{E}$ (equivalent to $\sim 5500 \mathrm{~km}$, spanning 3-4 times the west-east breadth of the Indian Peninsula), centering at the head of the western TP with its eastern flank covering nearly the entire

\section{(a) $250 \mathrm{hPa}$}
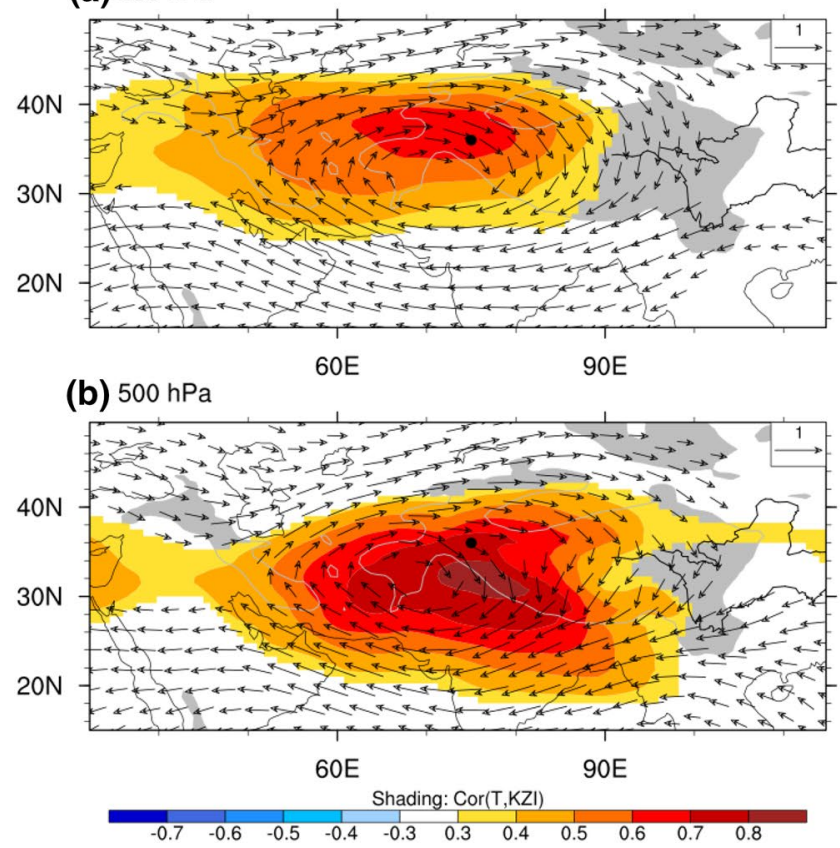

Fig. 1 Horizontal and vertical structures of the anti-cyclonic WTV (with positive intensity) in annual mean for 1979-2016. Horizontal structure (left panes: a, b) of the anti-cyclonic WTV is represented by correlations between the KZI and air temperature ( $\mathrm{T}$, colour-shading) and and vertical wind (arrows) vectors (V,W) at the a $250 \mathrm{hPa}$ and b $500 \mathrm{hPa}$ level (the near surface level of TP). Vertical structure (right panel: c) is represented by correlations between the KZI, T (colourshading), geopotential height (HGT, contour) and vertical wind
TP (Li et al. 2018), also see Fig. 1a, b. So, the WTV is a large-scale circulation pattern; and it is generally different from the synoptic-scale or meso-scale systems prevailing on daily and sub-monthly time scales over the western TP, such as the western disturbance (Pisharoty and Desai 1956; Ramanathan and Saha 1972; Dimri 2004; Feng et al. 2014; Hunt et al. 2017, 2018) and the Tibetan Plateau vortices (e.g.,Tao and Ding 1981).

The WTV is suggested (Li et al. 2019) not likely a thermally-direct circulation, as it has opposing vertical features (Fig. 1c) to a thermally-direct circulation: the anticyclonic WTV has a "warm high" structure at the near surface levels (Fig. 1b and Fig. 1c) above the western TP topography (i.e., the anticyclonic WTV is associated with warmer air temperature and higher pressure in the near-surface and the midlower-troposphere); and the cyclonic WTV, in contrast, has a "cool low" structure at the same levels (i.e., the cyclonic WTV is associated with cooler air temperature and lower pressure in the near-surface and the mid-lower-troposphere). Rather, FL1718 showed that its summer behaviour is likely influenced by both adiabatic heating, its coupling with the thermally-driven monsoon circulation and the subtropical westerly jet, which is in line with findings on the interactions

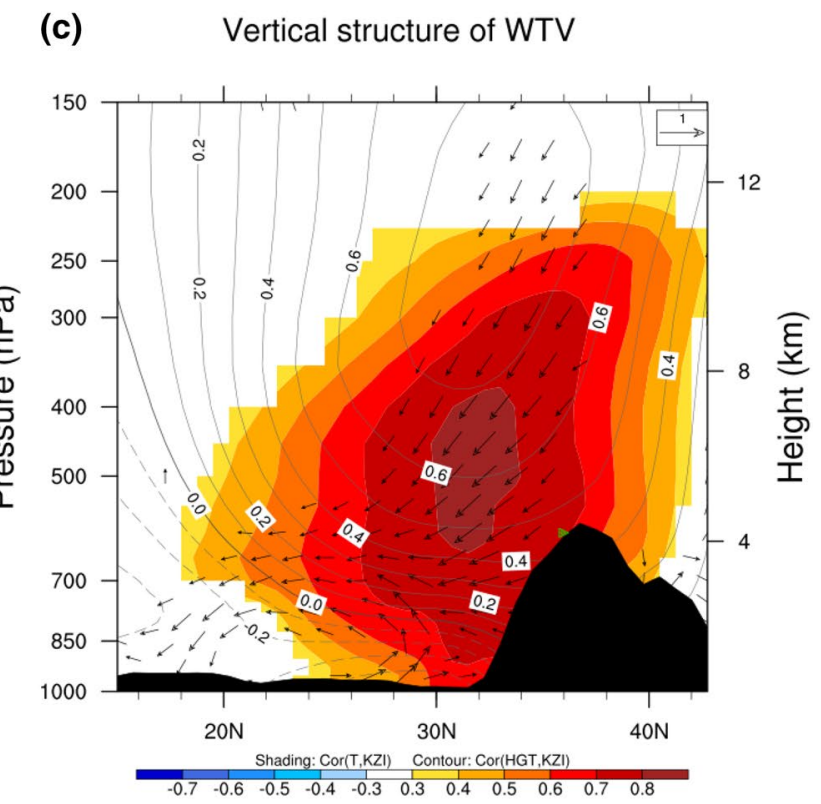

(arrows) vectors $(\mathrm{V}, \mathrm{W})$ along a latitudinal profile (across $70^{\circ} \mathrm{E}-80^{\circ}$ E). Only the correlations significant at 0.05 level after taking account of the efficient numbers of degrees of freedom are colour-shading (Zar 1984; Li et al. 2013a, b); a significant vector denotes either one of its components is significant. Grey shading in left panels denote topography above $1500 \mathrm{~m}$, black shading in (c) denote the topography. The black dots in left panels and green triangle in right panel denote the central Karakoram $\left(36^{\circ} \mathrm{N}, 75^{\circ} \mathrm{E}\right)$ 
between the circumglobal teleconnection (CGT) and the monsoon described above (e.g., Saeed et al. 2011).

Intuitively then, the anti-cyclonic trending in the WTV was used to explain (Forsythe et al. 2017; Bhambri et al. 2019) the development or maintenance of the "Karakoram Anomaly" (Hewitt 2005), an unusual glacier melting behaviour over Karakoram, i.e. the glaciers over the Karakoram and some neighbouring ranges did not show rapid retreats under the widespread warming and glacier retreat over Himalaya during recent decades (e.g., Hewitt 2005; Gardelle et al. 2012; Jacob et al. 2012; Kääb et al. 2012; Pratap et al. 2016; Bolch et al. 2017; Brun et al. 2017; Zhou et al. 2017; Farinotti et al. 2020). The "Karakoram Anomaly" is associated with that the summer temperatures have not been rising in the Karakoram (Fowler and Archer 2006; Khattak et al. 2011; Forsythe et al. 2012; Hasson et al. 2017), and the river flows in heavily glaciated basins of the Karakoram - a proxy for glacier melt in energy-limited catchments-have been stable or even declined (Fowler and Archer 2006; Sharif et al. 2013).

A few of studies have highlighted both the importance of a WTV-like circulation anomaly in this location in summer and its relationship with the interplay and mutual feedbacks between mid-latitude westerly and South Asian summer monsoon systems (e.g., Ding and Wang 2005; Krishnan et al. 2009; Saeed et al. 2011; Syed et al. 2012; Mölg et al. 2017). In particular, the WTV in summer shows marked similarities with the west-central Asian centre of action in a northern hemisphere summer CGT, which is principally located within a waveguide associated with the westerly jet stream (Ding and Wang 2005). Using a CGT index, Mölg et al. (2017) showed how a west-east (cold-warm) dipole in summer near-surface temperature anomalies across High Asia is associated with a southward shift in the upper-tropospheric westerly circulation, which is entirely consistent with the patterns linked to the WTV. The two-way interaction between the CGT and the South Asian summer monsoon proposed by Ding and Wang (2005) was also recently demonstrated using causal effect networks (Di Capua et al. 2020). It was found that mid-latitude circulation potentially exerts a larger causal influence on monsoon rainfall, although the latter system does feed back to the CGT, albeit more weakly.

However, de Kok and Immerzeel (2019, hereafter cited as dKI19) have recently raised a couple of arguments. The primary one is that the WTV is the change of wind field resulting from changes in near-surface temperature gradients in geostrophic flow. There are significant positive correlations between the intensity of the WTV and $2 \mathrm{~m}$ air temperature variability centring at the western TP (Fig. 2), which shrink to just over the western TP (above the altitude of $1500 \mathrm{~m}$ ) in summer and autumn (FL1718; Li et al. 2019). In other words, dKI19 suggested the WTV is a thermally-direct circulation generated from near-surface thermal forcing centring at the western Tibetan Plateau. Furthermore, dKI19 have assumed that surface net radiation likely drives nearsurface temperature variability, especially in summer and autumn, which in turn generates the WTV. In short, dKI19 believes that summertime surface net radiation causes changes of near-surface temperature variability, which, in turn, drives the WTV, basically opposing to previous studies (FL1718; Li et al. 2019).

If the WTV is indeed a thermally-direct circulation generated from the near surface heating, then it's hard to use the WTV or the WTV-like circulation variability to explain the glacier melting conditions and the near surface air temperature changes over the western TP, as did in Forsythe et al. (2017) and Mölg et al. (2017). In this study, we thereby carefully examine dKI19's putative thermal-direct mechanism by conducting a set of model sensitivity experiments, revisiting the radiation processes over the western TP. The remainder is arranged as the follows. Section 2 presents data, model and prescriptions of modeling experiments. The modeling results and their comparisons with the observed WTV are given in Sect. 3. In Sect. 4, we analyzed the radiation processes related to the WTV and surface air temperature variability in summer over the western TP based on the ERA 5 data. Then, the results and discussions are presented in Sect. 5 .

\section{Data and model}

\subsection{Data}

We use the ERA-Interim reanalysis (Dee et al. 2011) on both isobaric and sigma surfaces to present features of the observed WTV, as it has been shown to well represent near surface climate over the western TP high mountain areas (Forsythe et al. 2017). The use of the sigma surface is to remove the influence of topography in the lower troposphere. In plotting, we use a reversed Omega $\left(\mathrm{Pa} \mathrm{s}^{-1}\right.$, vertical velocity in the isobaric system) to represent vertical wind velocity, so a positive value of the vertical wind velocity denotes upward motion, and vice versa. This is a common way in plotting Omega in meteorology. The monthly Karakoram Zonal Index (KZI) is calculated following the formulations in Li et al. (2018), which is the measure of the intensity of the WTV originally defined in Forsythe et al. (2017). A positive KZI represents the anti-cyclonic phase of the WTV, which is associated with warmer air temperatures at both the near-surface and the mid-lower troposphere over the western TP. The observed positive KZI events during 1979-2010 used here are defined as same as Li et al. (2019).

We also employ the same surface net radiation scheme and the same KZI calculations (at the $300 \mathrm{hPa}$ level) for 

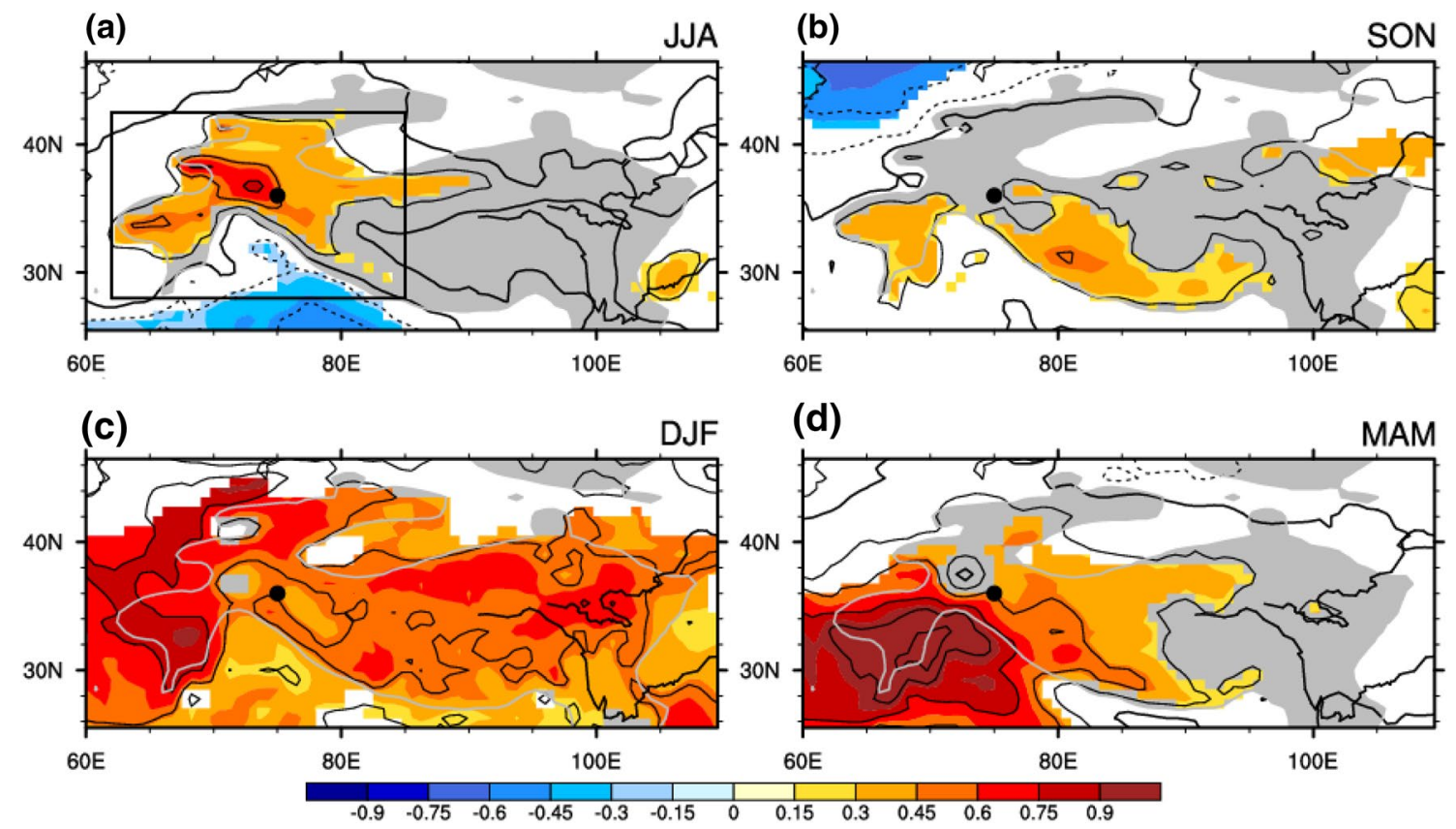

(d)

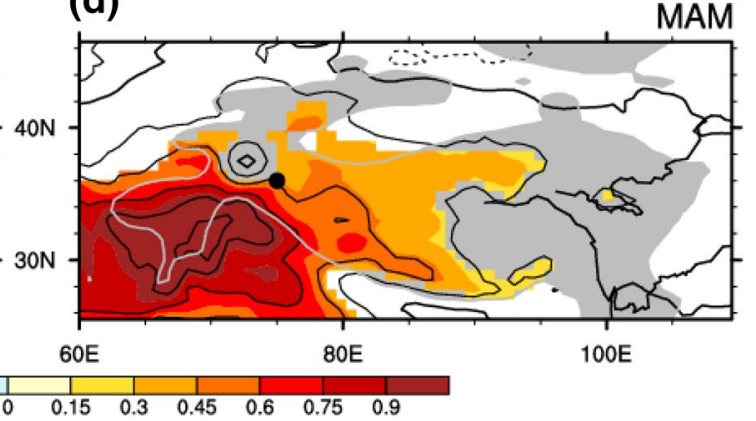

Fig. 2 Anomalous $2 \mathrm{~m}$ air temperature $\left(\mathrm{T}_{2 \mathrm{~m}}, \mathrm{~K}\right)$ at the anti-cyclonic WTV in four seasons, represented by linear regression of $T_{2 m}$ on standardized KZI (intensity index of WTV) using ERA-Interim reanalysis data. Color-Shading denotes significance at the 0.05 level after taking account of the efficient numbers of degrees of freedom

the ERA5 analysis used by dKI19 to test their arguments on radiation processes. It is important to note that further evaluations of the skills of the newly-released ERA5 dataset in representing atmospheric and thermal conditions over the western TP are still needed.

The anomalous circulation is then calculated as a departure from the climatological mean circulation during the reference period of 1979-2010 for consistency with FL1718. The climatological mean is separately assessed for each month of the annual cycle.

\section{Numerical model and experiments}

To examine the putative thermal-generating mechanism for the WTV proposed by dKI19, we employ SAMIL (version R42L26), a well-known (Wu et al. 2003; Wang et al. 2004) spectral atmospheric model developed at the State Key Laboratory of Numerical Modelling for Atmospheric Sciences and Geophysical Fluid Dynamics (LASG), Institute of Atmospheric Physics (IAP), Chinese Academy of Sciences (CAS). It has 26 pressure levels, $2.5^{\circ} \times 2.5^{\circ}$ in horizontal resolution and covers the global domain. SAMIL has been intensively used for Tibetan climate simulations (e.g., Wu et al. 2003).
(Zar 1984; Li et al. 2013a, b). Grey-shading denotes the topography above $1500 \mathrm{~m}$. Black rectangle is the region where the sensible heating is added on the TP topography surface (above $1500 \mathrm{~m}$ ) in sensitivity experiments of SAMIL. The black dots in left panels and green triangle in right panel denote the central Karakoram $\left(36^{\circ} \mathrm{N}, 75^{\circ} \mathrm{E}\right)$

We conduct sensitivity experiments using SAMIL. We choose summer to conduct the numerical experiments, as the WTV's impacts are more focused on the western TP topography (above 1,500 m) in summer relative to other seasons (Fig. 2; also see Li et al. 2018). Additionally, a thermally-direct circulation is also likely easier to develop in the warm season. Both the sensitivity and control runs are executed for 60 months with the solar zenith angle fixed at 15 July, so each month is equivalent to one summer in the model.

Sensitivity run A constant sensible heat flux (3 times the climatological mean of July) is added at the topography surface (with elevation higher than $1500 \mathrm{~m}$ ) over the western $\mathrm{TP}$ within the rectangular area in Fig. $3\left(28^{\circ} \mathrm{N}-42.5^{\circ} \mathrm{N}, 62^{\circ}\right.$ $\left.\mathrm{E}-87.195^{\circ} \mathrm{E}\right)$.

Control run Same as the sensitivity run, except that no extra sensible heat flux is added.

The simulated atmospheric circulation response to the surface thermal forcing is calculated as the mean difference of circulation in the sensitivity run minus the control run for the last 30 summers. Figure 3 shows the warmer near-surface air temperature over the western TP produced in SAMIL by adding a surface sensible heat flux; this mimics the thermal forcing conditions needed for the thermal-generating mechanism proposed by dKI19. 


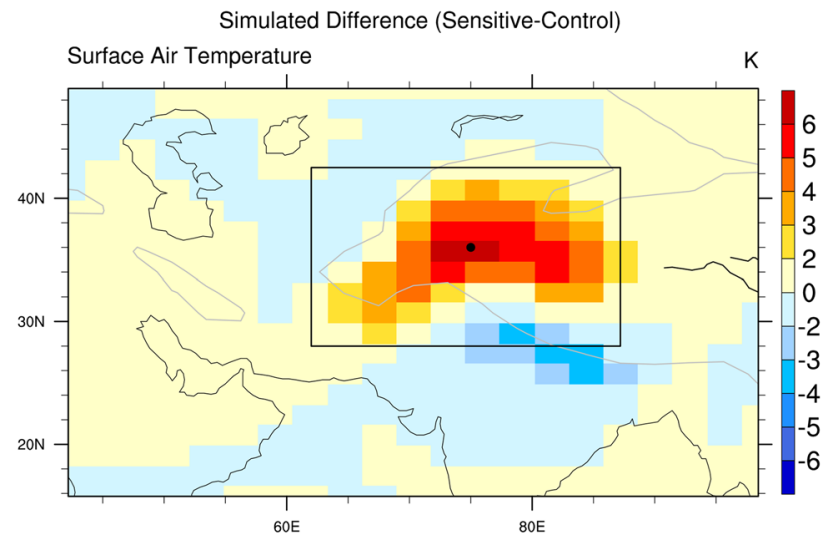

Fig. 3 The near-surface air temperature (SAT: colour-shading, K) response to near-surface sensible heat forcing in SAMIL, represented by the SAT differences between the thermal forcing sensitivity run and the control run. The sensible heat flux is added at the topography surface with elevation higher than $1500 \mathrm{~m}$ within the black rectangle area $\left(28^{\circ} \mathrm{N}-42.5^{\circ} \mathrm{N}, 62^{\circ} \mathrm{E}-87.195^{\circ} \mathrm{E}\right)$

\section{Modelling results}

We find that the response of the atmospheric circulation over the western TP to the surface thermal forcing maintains the structure of a classic thermally-direct circulation, featuring anomalous rising motions and a baroclinic structure; the opposite structure to the WTV. The details of horizontal and vertical structures of the WTV can be retrieved in $\mathrm{Li}$ et al. (2018).

\subsection{Simulated rising motions}

Figure 4a shows that significant upward motions (warmcolor shading) occur above ground surface of the western TP as a response to the addition of a surface sensible heat flux in SAMIL. This extends up from the ground surface to near the tropopause at $200 \mathrm{hPa}$. In contrast, the observed WTV (Fig. 4b) features anomalous downward motions (cold-color shading) within the central column of the WTV above the western TP, centred on the mid-upper troposphere around $400 \mathrm{hPa}$. The simulated response to surface heating in the vertical velocity is therefore the reverse of what occurs in the observed central column of the WTV.

\subsection{Simulated baroclinic structure in pressure and wind fields}

The baroclinic structure of the simulated thermally-direct circulation above the ground surface of the western TP is seen in both the pressure and wind fields. Higher pressure (represented by the higher geopotential heights of isobar surfaces) at the upper troposphere and lower pressure (represented by the lower geopotential heights of isobar surfaces) at the bottom of the troposphere above the ground surface of the western $\mathrm{TP}-\mathrm{a}$ classic baroclinic feature in the pressure field-is observed in the vertical profile of the thermallydirect circulation driven by the near-surface thermal forcing in SAMIL (Fig. 4c). In contrast, the pressure in the observed WTV is high at both the mid-low and mid-high troposphere, but centred on the mid-high troposphere, exhibiting as a quasi-barotropic structure (Fig. 4d).

The baroclinic structure of the thermally-direct circulation can be seen more clearer in the wind field. Figure $4 \mathrm{e}$ shows a significant anti-cyclone in the mid-high troposphere, but a significant cyclonic wind anomaly in the mid-low troposphere. The anti-cyclonic (cyclonic) winds at the mid-high (mid-low) troposphere are evidenced by both the significantly greater (smaller) stream function and greater (smaller) anomalous zonal wind shear at the according isobaric surfaces. In contrast, anti-cyclonic wind anomalies exist in both the mid-high and mid-low troposphere in the observed WTV (Fig. 2f), but are centred at the mid-high troposphere.

\subsection{Simulated surface pressure}

Classic theory tells us that surface-thermal forcing should to cause lower surface pressure (Holton 2004), which is consistent with a baroclinic structure of a thermally-direct circulation in pressure fields. We therefore also examine the surface pressure fields (Fig. 5). Comparing Fig. 5a, b, we can see significantly lower surface pressure and anomalous cyclonic winds near the ground surface occur in response to the sensible surface heat flux over the western TP in SAMIL, but non-significant surface pressure variability and cyclonic wind anomalies exist in the observed WTV. Furthermore, in spring and winter, the surface pressure (see Fig. 6) associated with warmer $T_{2 m}$ (Fig. 2) over the western TP is significantly increased rather than decreased. This discrepancy between the simulation and the observations implies that the surface pressure anomalies in the observed WTV are not directly driven by surface heating.

In summary, we find that the thermal forcing experiment produces (1) anomalous rising motions with (2) a classic thermally-direct circulation structure in the pressure, horizontal wind fields above the wester TP topography, the opposite of a WTV-like structure. These experiments demonstrate that surface (or bottom of atmosphere) thermal forcing cannot generate a WTV-like structure.

Although the thermal forcing does not generate the WTV, we find the surface thermal forcing does impact the WTV. It enhances the anti-cyclonic WTV at the upper troposphere by amplifying the pressure (Fig. 4c) and the zonal wind shear (Fig. 4d), but weakens the anti-cyclonic WTV at the lower troposphere by reducing the pressure (Fig. 4c) and the zonal wind shear (Fig. 4d). This means that the surface thermal forcing may contribute as a key factor in the feedback 
Simulated Difference (Sensitve-Control)

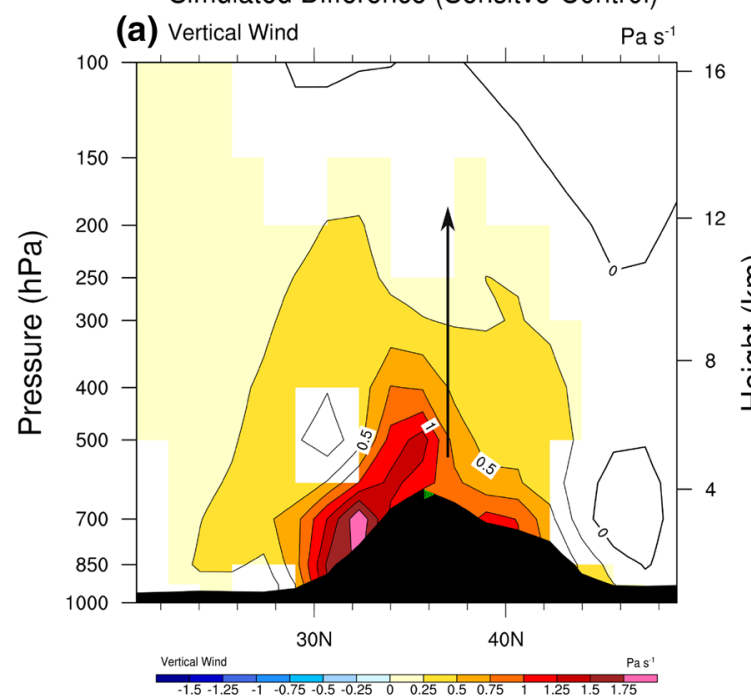

(c) Geopotential Height

gpm

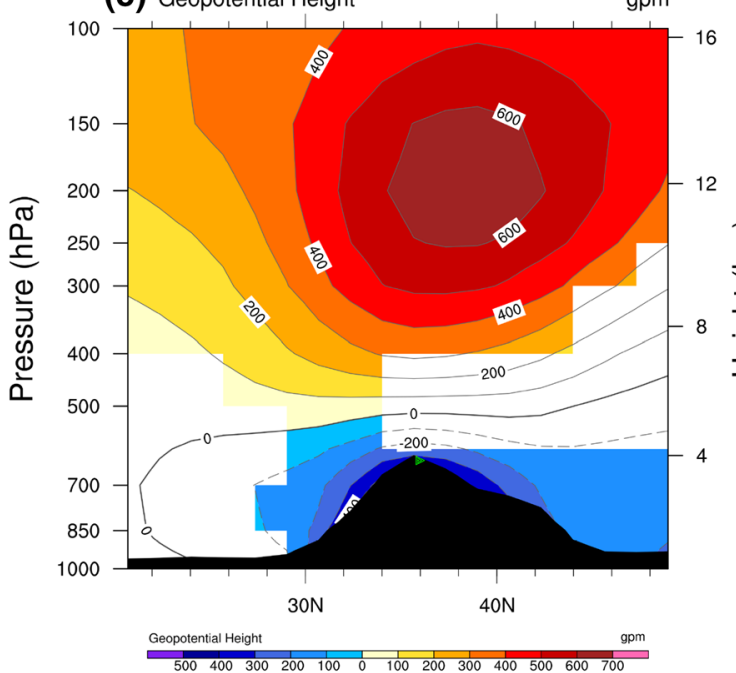

(e) Stream function (shading: $10^{6} \mathrm{~m}^{2} \mathrm{~s}^{-1}$ ), Zonal wind (cont: $\mathrm{m} \mathrm{s}^{-1}$ )

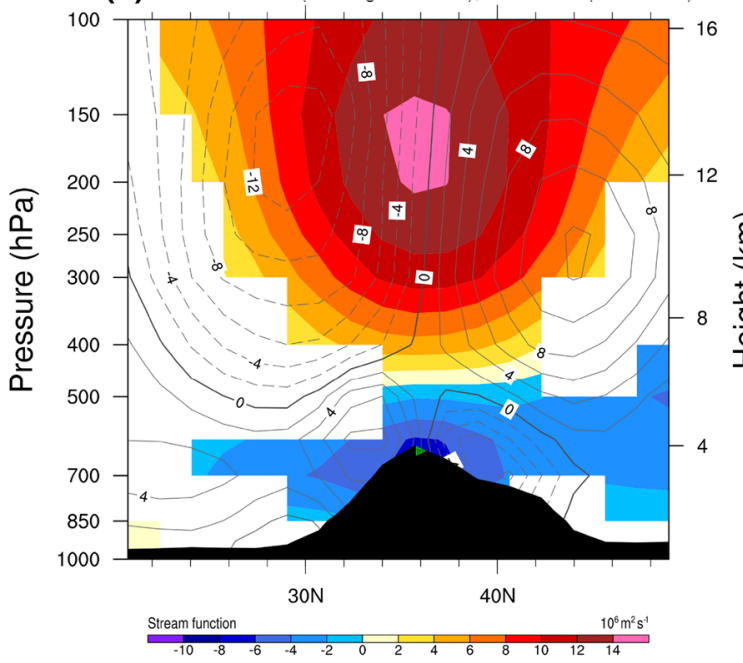

Observed WTV

(b) Vertical Wind
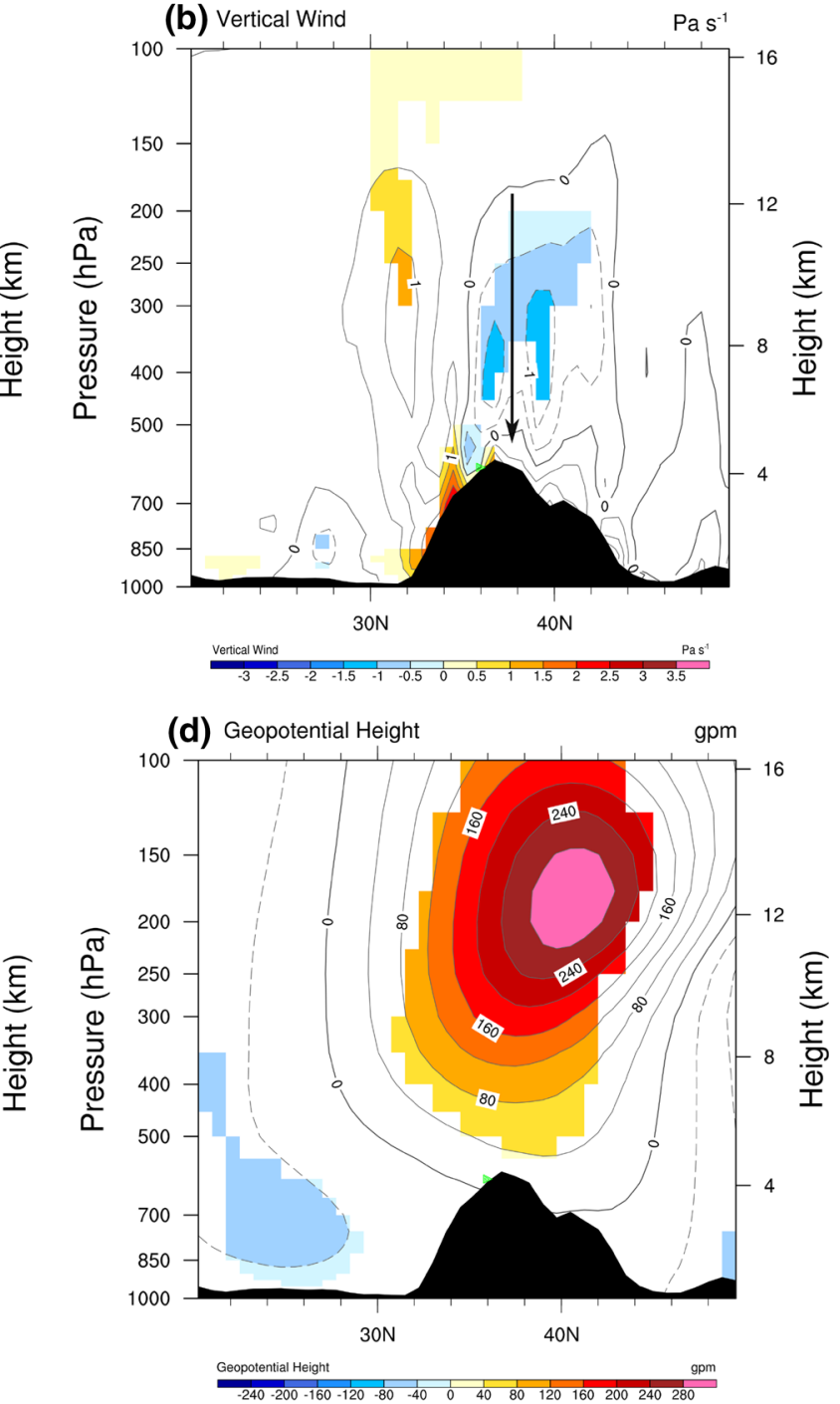

(f) Stream function (shading: $\left.10^{6} \mathrm{~m}^{2} \mathrm{~s}^{-1}\right)$, Zonal wind (cont: $\mathrm{m} \mathrm{s}^{-1}$ )

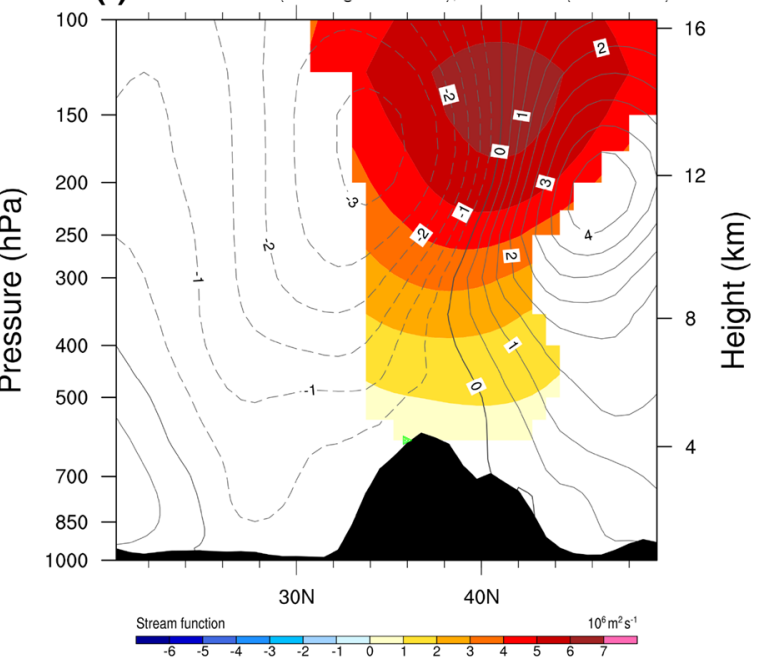


४Fig. 4 Comparison of the meridionally-averaged $\left(70^{\circ} \mathrm{E}-80^{\circ} \mathrm{E}\right)$ vertical profiles between simulated thermally-direct circulation (left column: a, c, e) in SAMIL (sensitivity-control) and the observed WTV (right column: b, d, f) in its anti-cyclonic phase (which is associated with warmer $\mathrm{T}_{2 \mathrm{~m}}$ ) in ERA-Interim. a, b Vertical velocity anomalies, c, $\mathbf{d}$ are geopotential height anomalies, $\mathbf{e}, \mathbf{f}$ are zonal wind (U, contours) and stream function (SF, colour-shading, only shows the values significance at 0.05 level). Vertical velocity anomalies in $\mathbf{a}, \mathbf{b}$ are represented by the reversed omega but are amplified to similar magnitudes for better comparison. Colour shading denotes significance at the 0.05 level, after considering the equivalent sample size (Zwiers and von Storch 1995). Black shading denotes the smoothed western TP topography (across the $75^{\circ} \mathrm{E}$ )

processes causing the WTV to present as a quasi-barotropic rather than an ideally barotropic structure. This potential feedback mechanism merits further investigation, but such analyses are beyond the scope of this study.

\section{Impacts of the WTV on radiation processes}

We now further examine impacts of the WTV on variability in surface net radiation and near-surface air temperature $\left(\mathrm{T}_{2 \mathrm{~m}}\right)$ over the western TP, moving beyond the simple theory proposed by dKI19 that surface net radiation likely drives near-surface air temperature due to significant correlation between surface net radiation and $\mathrm{T}_{2 \mathrm{~m}}$ over the western TP. We find that the surface net radiation (positive value means incoming net radiation) itself may be modulated by the WTV through cloudiness over the western TP.

The significant positive correlation between surface net radiation (sum of surface net shortwave radiation and surface net longwave radiation) and $\mathrm{T}_{2 \mathrm{~m}}$ over the western TP (as documented by dKI19) is verified well in Fig. 7a. Moreover, our further analysis reveals that this positive correlation mainly comes from a positive correlation between the surface net shortwave (or solar) radiation and the $\mathrm{T}_{2 \mathrm{~m}}$ (Fig. $7 \mathrm{c}$ vs b). Net surface shortwave radiation is known as a major driver (e.g., Wan and Dozier 1996; Sobrino et al. 2004; Li et al. 2013b) of land surface temperature changes, and a warmer or cooler ground surface, in turn, impacts the $T_{2 m}$ by direct heat conduction, longwave radiation and evaporative cooling processes. Therefore, the surface net shortwave radiation is a key influence on $\mathrm{T}_{2 \mathrm{~m}}$.

Surface net shortwave radiation is heavily influenced by cloudiness. We now examine how modes of the WTV affect total cloud cover over the western TP and the Karakoram (Fig. 8). We find that an anti-cyclonic (cyclonic) WTV reduces (increases) the cloudiness over the western TP (Fig. 8d), causes more (less) net surface shortwave radiation (Fig. 8c) and net surface radiation (Fig. 8b), resulting in higher (lower) land surface temperature and $\mathrm{T}_{2 \mathrm{~m}}$ (Fig. 8a) over the western TP. And the impacts of the anti-cyclonic (cyclonic) WTV on the cloudiness are likely primarily due to its associated anomalous sinking (rising) motions over the western TP. In short, the variability of surface net shortwave radiation and $\mathrm{T}_{2 \mathrm{~m}}$ can be traced back to WTV variability.

Bold values marked by "**” and "+" respectively denotes significant at 0.05 and 0.10 level, after considering the efficient numbers of degrees of freedom.

Over the Karakoram (shown as a green box in Fig. 8), we find that reduced (increased) cloud is responsible for greater (smaller) surface net shortwave radiation, as their correlation is -0.53 , significant at the 0.05 level (Table 1 ). Variability of the surface net shortwave radiation provides the majority of explained variance ( $>72 \%$ variance) of the surface net radiation, as they are tightly covariant to each other (Fig. 8e) with their correlation reaching as high as 0.85 (Table 1). Because the KZI is also significantly correlated ( -0.38 , see Table 1) with the total cloudiness in ERA5 data, we conclude that the WTV may impact the $\mathrm{T}_{2 \mathrm{~m}}$ over Karakoram by modulating the cloudiness and therefore the surface net shortwave radiation.

In short, the WTV appears to impact $\mathrm{T}_{2 \mathrm{~m}}$ through modulating cloudiness over sub-regions of the western TP, including the Karakoram area, but more numerical experiments are needed to verify this hypothesis based on observational analysis. This complements previous work which found that adiabatic sinking-compression (rising-expansion) provides the overwhelming control on middle-to-lower tropospheric temperature variability in the region, but that diabatic heating has localized importance over the edges of the western TP (Li et al. 2019). We also note that surface net radiation has no significant correlation with $\mathrm{T}_{2 \mathrm{~m}}$ over southwest parts of the western TP (Fig. 7a), where $\mathrm{T}_{2 \mathrm{~m}}$ is still significantly influenced by the WTV (Fig. 7a). This means that radiation does not drive $\mathrm{T}_{2 \mathrm{~m}}$ variability there, and multiple mechanisms exist for the WTV to influence $\mathrm{T}_{2 \mathrm{~m}}$ over sub-regions of the western TP, which have already been emphasized by Li et al. (2019).

\section{Conclusions and discussions}

An analysis of the thermal wind equation can hardly provide a definitive attribution of whether wind drives temperature or the reverse. Because the thermal wind equation reflects only an internal balance/relationship between the (horizontal gradient of) temperature and the (vertical shear of) geostrophic wind in geostrophic flows (see Holton (2004) for the basic theory). The thermal wind equation is often used to check analyses of observed wind and temperature fields for consistency in large-scale extratropical systems, and to estimate the mean horizontal temperature advection in a layer (Holton 2004). In the mid- to high latitudes, "the comparatively large-scale atmospheric 


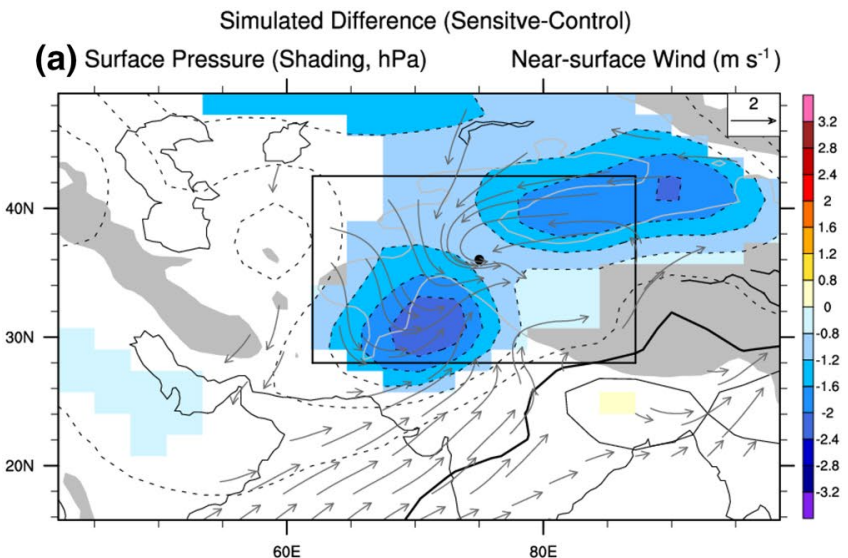

Fig. 5 The surface pressure anomalies (color shading and contours) and anomalous near-surface wind vector (at 0.92 sigma level) a in response to near-surface thermal forcing in SAMIL (sensitivitycontrol), and b composited in observed WTV's anti-cyclonic phase (which is associated with warmer near-surface air temperature) in

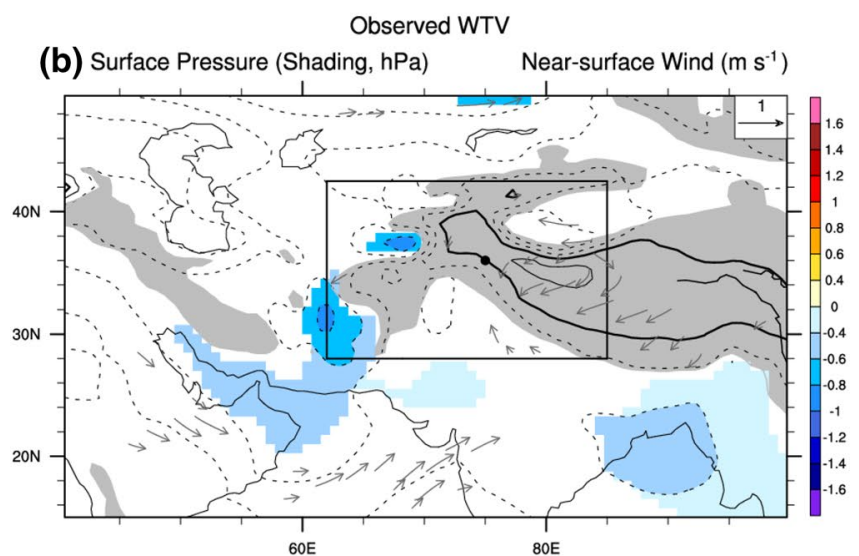

ERA-Interim. Color shading denotes significance at the 0.05 level, after considering the equivalent sample size (Zwiers and von Storch 1995). Only anomalous wind vectors significant at 0.05 level are plotted. Black rectangle area represents the area adding the sensible heating in the SAMIL
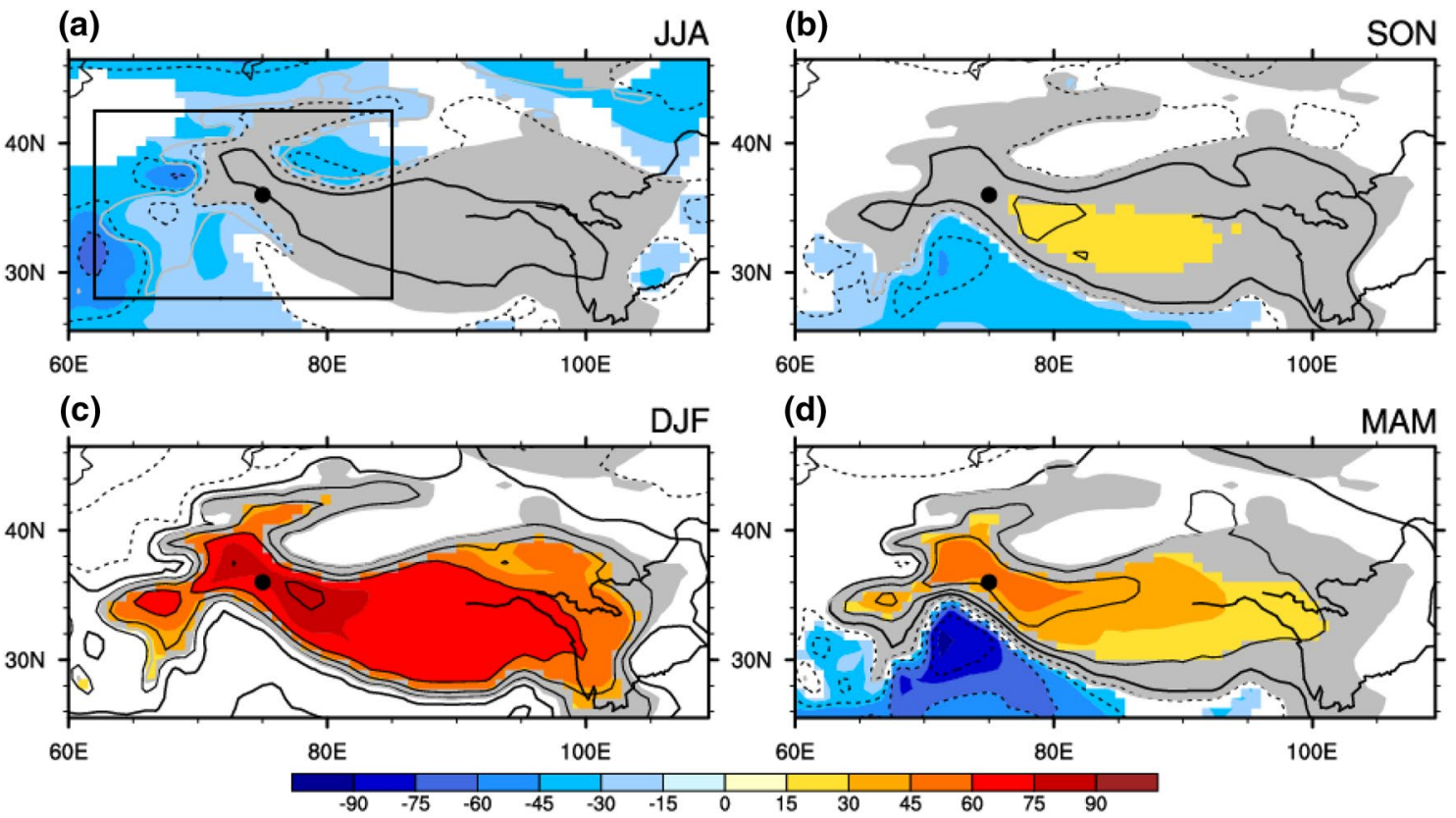

(d)

MAM

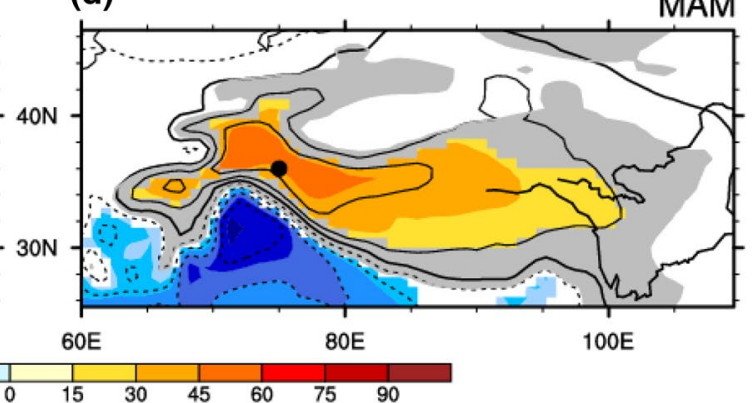

Fig. 6 Observed surface pressure anomalies (hPa) at the anti-cyclonic WTV in four seasons, represented by linear regression of surface pressure on the standardized KZI (intensity index of WTV) using ERA-Interim reanalysis data. Color-shading denotes significance at 0.05 level after taking account of the efficient degrees of freedom

motions are fundamentally quasi-geostrophic" (Yeh 1957), so the large-scale wind and temperature fields are generally consistent and satisfy the thermal wind equation, which explains the generally high correlations between them in the extra-tropics. It's thereby hard to use this generally existing consistency to assert that temperature drives wind changes or the reverse, as the two 'directions
(Zar 1984; Li et al. 2013a, b). Grey-shading denotes the topography above $1500 \mathrm{~m}$. Black rectangle is the region where the sensible heating is added on the TP topography surface in sensitivity experiments of SAMIL

of causality' are both possible. For example, the Ferrell Cell in each hemisphere is driven by eddy forcing (Holton 2004) rather than the meridional temperature gradient at the mid-latitudes, but its temperature and wind fields still satisfy the thermal wind equation. So numerical experiments are needed and carried out in this study to assess the putative thermal-direct mechanism of the WTV. 
Fig. 7 Pearson correlations between KZI and $\mathbf{a} \mathrm{T}_{2 \mathrm{~m}}, \mathbf{b}$ surface net radiation (sum of the surface shortwave net radiation and longwave net radiation), $\mathbf{c}$ surface net shortwave radiation during summer (JJA) season in the period of 1979-2018 in ERA5 monthly data. The stippling denotes significance above the 0.10 level, after taking account of the efficient number of degrees of freedom (Zar 1984; Li et al. 2013a, b). The green star denotes the central position $\left(36^{\circ} \mathrm{N}, 75^{\circ} \mathrm{E}\right)$ of the Karakoram focus area, the green square denotes area of $35^{\circ} \mathrm{N}-37^{\circ} \mathrm{N}, 74^{\circ} \mathrm{E}-76^{\circ} \mathrm{E}$. The bold-black-outline denotes topography above $1500 \mathrm{~m}$
Correlations between $T_{2 m}$ and surface radiations (JJA)

\section{(a) Surface net radiation and heat flux}

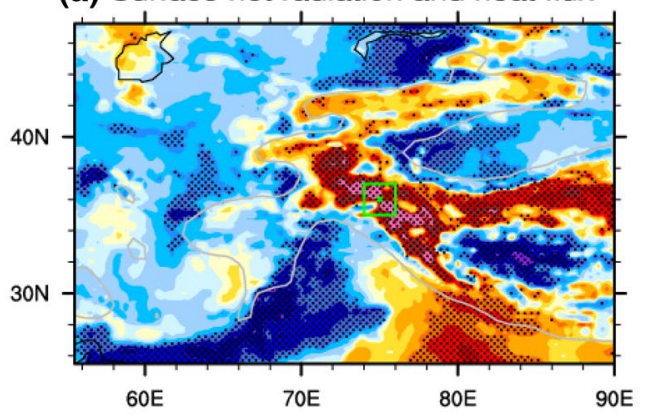

(b) Surface net longwave radiation

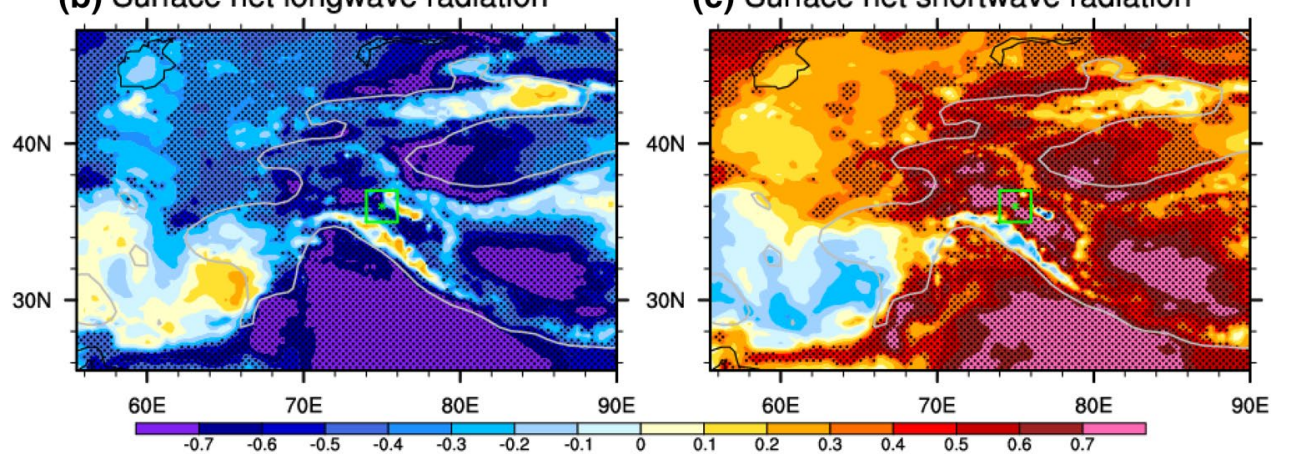

Here, we note the numerical experiments with a surface sensible heat flux imposed over the ground surface of the western TP (above $1500 \mathrm{~m}$ within the area of $28^{\circ} \mathrm{N}-42.5^{\circ}$ $\left.\mathrm{N}, 62^{\circ} \mathrm{E}-87.195^{\circ} \mathrm{E}\right)$ using a global atmospheric circulation model, the SAMIL (version R42L26), however, were unable to produce circulation anomalies exhibiting the key characteristics of the WTV. On the contrary, these simulations produced only classical thermally-direct circulations right above the thermal forcing, featuring

1. anomalous rising motions, and

2. a baroclinic structure above the ground surface of the western TP (above $1500 \mathrm{~m}$ ), is basically the opposite to the WTV structure, as shown as Fig. 9.

These simulations are reasonable according to the basic theory of the thermally-direct circulation (e.g., Halley 1687; Ye and Wu 1998; Wu and Liu 2000; Holton 2004), and are also in line with previous thermal-forcing simulations conducted over different parts of the TP (e.g., Wu et al. 2007; Wang et al. 2018).

Instead of generating the WTV, we find surface thermal forcing over the western TP may impact the WTV, which needs more discussions. The surface thermal forcing seemly enhances the WTV at the mid-high troposphere but weakens it at the mid-low troposphere. Further analysis may be needed to establish whether it can provide an explanation for why the WTV has a quasi-barotropic rather than a barotropic structure. It should also be noted that the vertical structure of the WTV extends downward from the upper troposphere to the near surface level over the topography of the western TP all year around, but it is generally shallower in summer and autumn seasons than in winter and spring seasons ( $\mathrm{Li}$ et al. 2018). This arises another interesting question about what is the role played by the surface thermal forcing over the plain areas nonboring the western TP, which deserves further study.

But, the arguments of dKI19 do encourage the further explorations on radiation processes relevant to the WTV that is constructive. Our further explorations based on ERA5 data suggest the WTV may impact near-surface temperature and net radiation through the modulation of cloudiness over the western TP. Under the anti-cyclonic WTV, the anomalous sinking motions cause less cloudiness and more input shortwave (solar) radiation, which warms the (skin) surface temperature and near-surface air temperature. Under the cyclonic WTV, however, the anomalous rising motions cause more cloudiness and less input shortwave (solar) radiation, which cools the (skin) surface temperature and near-surface air temperature (Fig. 10). We note that the correlation between surface temperature and total cloud cover is not significant over the central Karakorum area (as shown in Table 1), which suggests the total cloud cover is not the only factor influences the radiations. The contribution of land surface ice/snow cover in response to the WTV may be another important force in modulating the surface 
Fig. 8 Pearson correlations (upper panel) between KZI and a $\mathrm{T}_{2 \mathrm{~m}}$, b surface net radiation, $\mathbf{c}$ surface net shortwave radiation, d) total cloud cover during summer (JJA) season, and e the area mean of the standardized time series (bottom panel) of the latter three variables over the central Karakoram (green square in $\mathbf{a}-\mathbf{d}$ ), in the period of 1979-2018 in ERA5 monthly data. The stippling denotes significance above the 0.10 level, after taking account of the effective number of degrees of freedom (Zar 1984; Li et al. 2013a, b). The green star denotes the central position $\left(36^{\circ}\right.$ $\mathrm{N}, 75^{\circ} \mathrm{E}$ ) of the Karakoram focus area, the green square denotes area of $35^{\circ} \mathrm{N}-37^{\circ} \mathrm{N}$, $74^{\circ} \mathrm{E}-76^{\circ} \mathrm{E}$. The bold-blackoutline denotes topography above $1500 \mathrm{~m}$
Table 1 Cross correlations among variables over the central Karakoram area $\left(35^{\circ} \mathrm{N}-37^{\circ} \mathrm{N}\right.$, $\left.74^{\circ} \mathrm{E}-76^{\circ} \mathrm{E}\right)$ during summers of 1979-2018 in ERA5 data

\section{Correlations with $\mathrm{KZI}$ in JJA}

(a) $T_{2 m}$

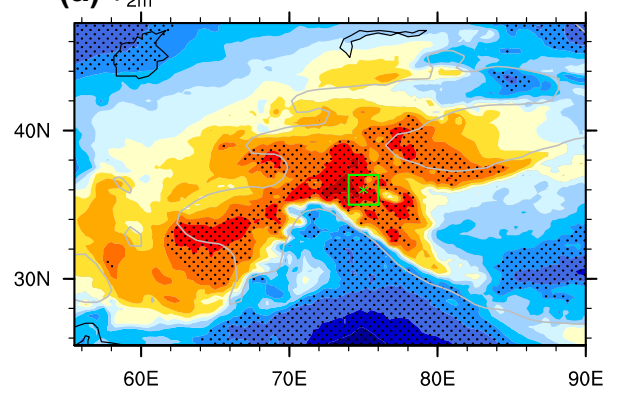

(c) Surface net shortwave radiation

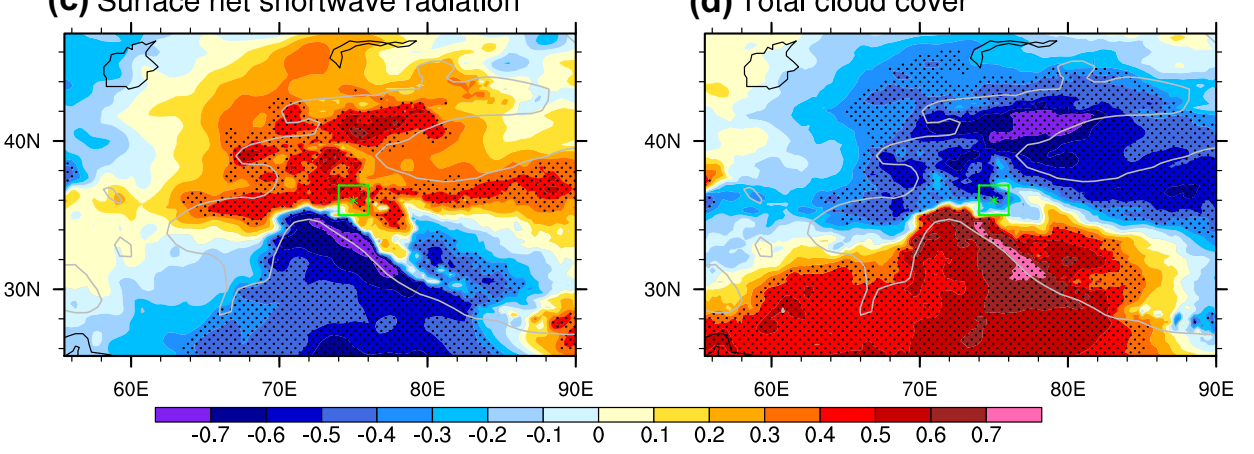

(e) Karakoram

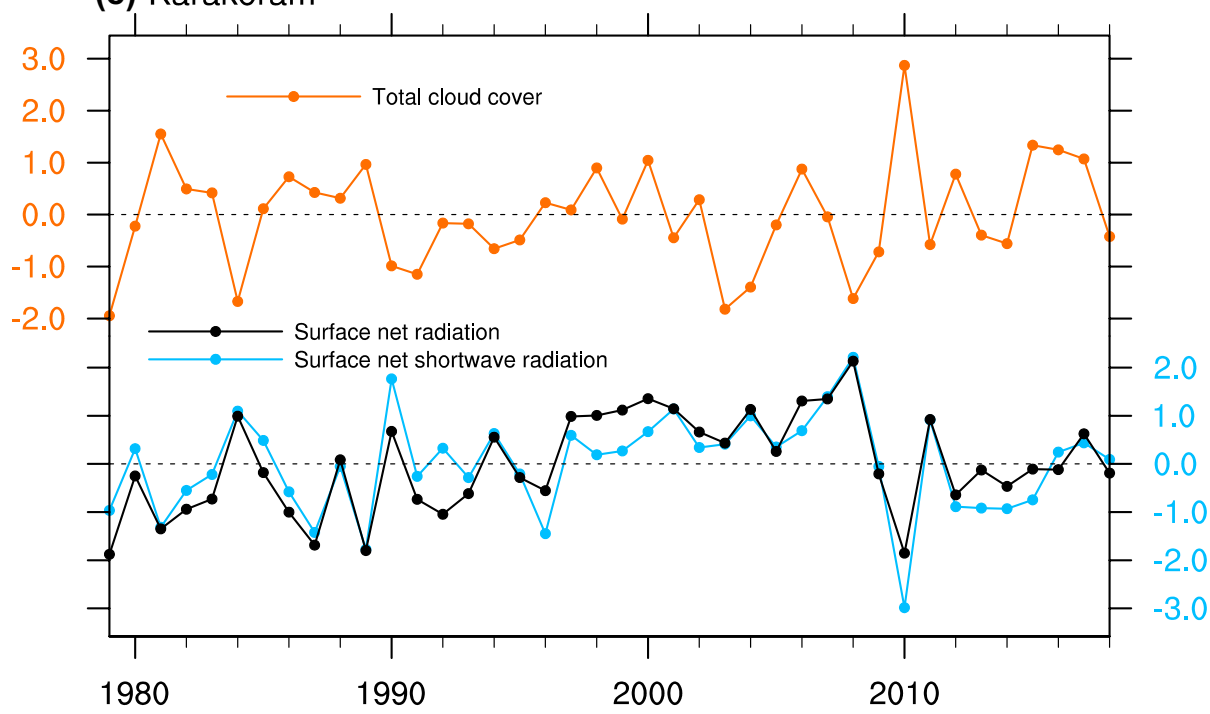

\begin{tabular}{llllll}
\hline & KZI & $\mathrm{T}_{2 \mathrm{~m}}$ & $\begin{array}{l}\text { Surface net } \\
\text { radiation }\end{array}$ & $\begin{array}{l}\text { Surface net short- } \\
\text { wave radiation }\end{array}$ & Total cloud cover \\
\hline KZI & 1 & $\mathbf{0 . 4 7 *}$ & $\mathbf{0 . 3 5 *}$ & $\mathbf{0 . 4 3}^{*}$ & $\mathbf{- 0 . 3 8 ^ { * }}$ \\
$\mathrm{T}_{2 \mathrm{~m}}$ & & 1 & $\mathbf{0 . 6 4 *}$ & $\mathbf{0 . 6 4}^{*}$ & -0.11 \\
Surface net radiation & & & 1 & $\mathbf{0 . 8 5}^{*}$ & $\mathbf{- 0 . 3 0 ^ { + }}$ \\
Surface net shortwave radiation & & & & 1 & $\mathbf{0 . 5 3 *}$ \\
Total cloud cover & & & & & 1 \\
\hline
\end{tabular}

Bold values marked by “*” and " + " respectively denotes significant at 0.05 and 0.10 level, after considering the efficient numbers of degrees of freedom. 

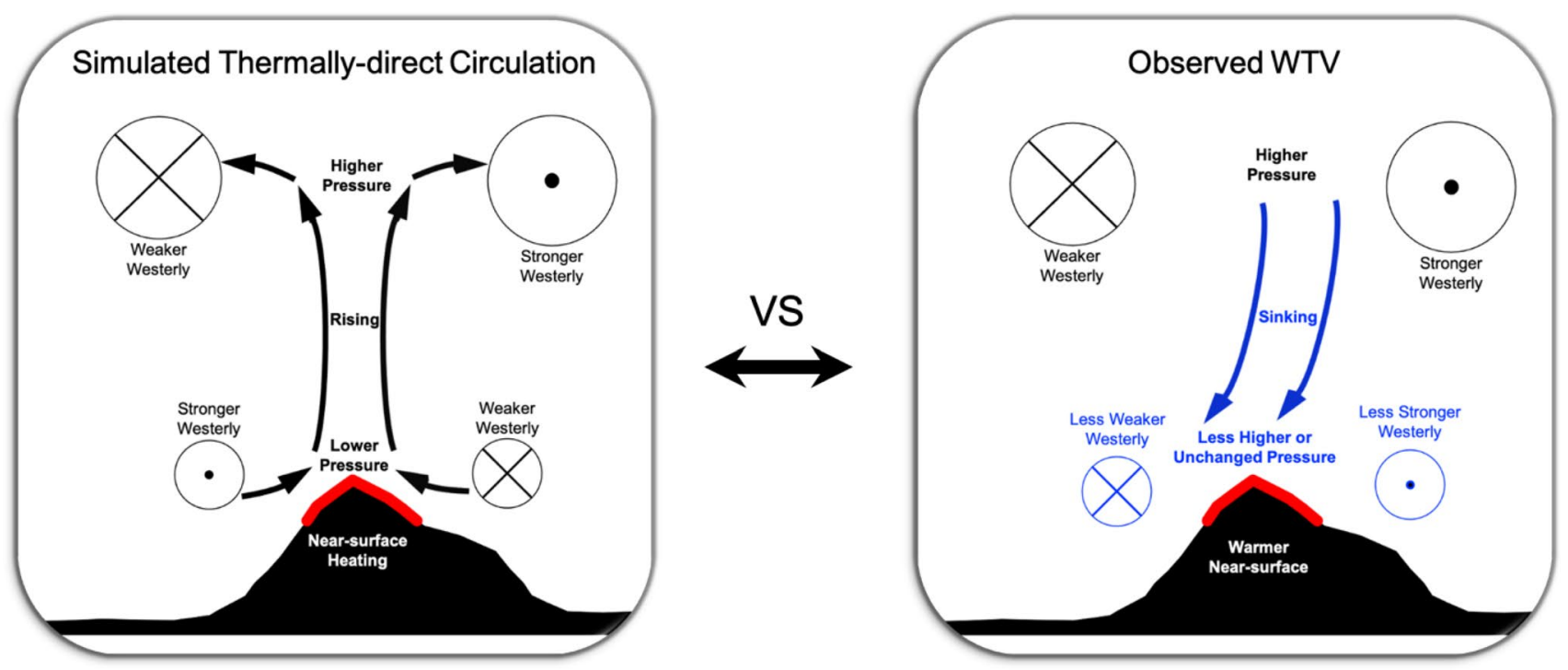

Fig. 9 Comparison of the conceptional vertical structures of the simulated thermally-direct circulation (left panel) and the observed anti-cyclonic WTV (right panel) within the troposphere (below $\sim 150 \mathrm{hPa}$ ). Left panel is very close to an idealized thermally-

radiative balance and requires more discussion in the future. It is also important to note that further evaluations of the skills of the newly released ERA5 dataset in representing atmospheric and thermal conditions over the western TP are still needed, as considerable bias in ERA5 reanalysis has been reported recently neighbouring the western TP (e.g., Jiang et al. 2021).

Previously, by diagnosing the classic thermal energy equation, a tendency equation of the air temperature, using the ERA-Interim reanalysis data, Li et al. (2019) demonstrated that adiabatic processes-i.e. the sinking-compressing-warming/rising-expanding-cooling-are the dominant contributor through which the WTV impacts the air temperature in the mid-lower troposphere and at the near-surface level (500 hPa) over the western TP. Li et al. (2019) found that two other types of major thermodynamic processes: diabatic processes (i.e. sensible heating, radiative heating and latent heating processes) and horizontal temperature convection (i.e. warm/cold currents) are also important in sub-regions of the western TP. Li et al. (2019) then proposed that the thermodynamic processes at the near-surface level over the western TP at around $500 \mathrm{hPa}$ can generally explain the $\mathrm{T}_{2 \mathrm{~m}}$ responses over the western TP high mountain areas. Further investigation of the radiation processes central to this study complement and enhance our understanding of the mechanisms through which the WTV influences the western TP's surface climates, including the $\mathrm{T}_{2 \mathrm{~m}}$ changes. Of course, substantial additional verification work especially the numerical simulations will be needed for this to come to fruition. For example, whether high-resolution regional direct circulation depicted at the Page 78 of Holton (2004). Right panel is summarized from the seasonal profiles presented in $\mathrm{Li}$ et al. (2018). Thick black shading at the bottom of each panel denotes the western TP topography

\section{Atmospheric Circulation}

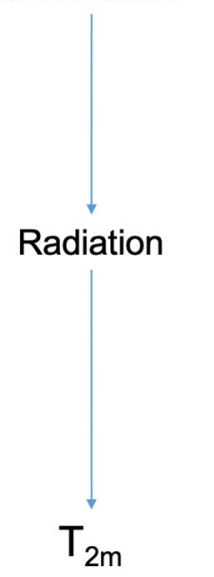

Anti-cyclonic WTV

(anomalous sinking)

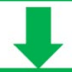

Less cloudiness

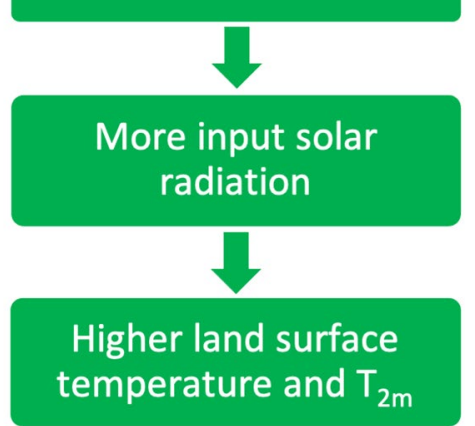

Fig. 10 Assumed physical diagram of anti-cyclonic WTV's influences on $2 \mathrm{~m}$ air temperature $\left(\mathrm{T}_{2 \mathrm{~m}}\right)$ over the western TP through modulating the surface radiation processes

climate or weather models can reproduce the radiative processes related to the WTV variability needs further examination. A specific unresolved research question concerns what proportion of WTV influence on $\mathrm{T}_{2 \mathrm{~m}}$ is through the cloud radiative effects related to direct thermodynamic processes (including adiabatic processes and horizontal temperature convection). Meaningfully answering this question will 
depend greatly on the accuracy of the sparse observational data over the western TP. Another interesting question concerns whether the cloud radiative effects play the same role at higher surface elevations where there is semi-permanent or permanent snow packs versus at lower elevations with intermittent snow cover on the western TP that far above the sea level.

Acknowledgements We thank Prof. Fei-Fei Jin (University of Hawaii, USA), Prof. Hayley J. Fowler (Newcastle University, UK), Dr. David Pritchard (Newcastle University, UK), Dr. Nathan Forsythe (Newcastle University, UK), Prof. Jianhua Lv (Sun Yat-sen University, China), and three anomalous reviewers for their constructive discussions during the formation of this study. This study is funded by Natural Science Foundation of China under grants 42088101 and 42175026, the Guangdong Province Key Laboratory for Climate Change and Natural Disaster Studies (Grant 2020B1212060025), the Natural Science Foundation of China under grant 41875128 . ERA Interim data are publicly available from https://www.ecmwf.int/en/forecasts/datasets/reanalysis-datasets/ era-interim. ERA5 data are publicly available from https://www.ecmwf. int/en/forecasts/datasets/reanalysis-datasets/era5.

Open Access This article is licensed under a Creative Commons Attribution 4.0 International License, which permits use, sharing, adaptation, distribution and reproduction in any medium or format, as long as you give appropriate credit to the original author(s) and the source, provide a link to the Creative Commons licence, and indicate if changes were made. The images or other third party material in this article are included in the article's Creative Commons licence, unless indicated otherwise in a credit line to the material. If material is not included in the article's Creative Commons licence and your intended use is not permitted by statutory regulation or exceeds the permitted use, you will need to obtain permission directly from the copyright holder. To view a copy of this licence, visit http://creativecommons.org/licenses/by/4.0/.

\section{References}

Bhambri R, Hewitt K, Kawishwar P, Kumar A, Verma A, Snehmani ST, Misra A (2019) Ice-dams, outburst floods, and movement heterogeneity of glaciers, Karakoram. Glob Planet Change 180:100116. https://doi.org/10.1016/j.gloplacha.2019.05.004

Bjerknes J (1969) Atmospheric teleconnections from the equatorial pacific. Mon Weather Rev 97:163-172

Bolch T, Pieczonka T, Mukherjee K, Shea J (2017) Brief communication: glaciers in the Hunza catchment (Karakoram) have been nearly in balance since the 1970s. Cryosphere 11:531-539

Brun F, Berthier E, Wagnon P, Kääb A, Treichler D (2017) A spatially resolved estimate of High Mountain Asia glacier mass balances from 2000 to 2016. Nat Geosci 10:668-673. https://doi.org/10. 1038/ngeo2999

Cornejo-Garrido AG, Stone PH (1977) On the heat balance of the Walker circulation. J Atmos Sci 34:1155-1162

de Kok RJ, Immerzeel WW (2019) The Western Tibetan Vortex as an emergent feature of near-surface temperature variations. Geophys Res Lett. https://doi.org/10.1029/2019g1085757

Dee DP, Uppala SM, Simmons AJ, Berrisford P, Poli P, Kobayashi S, Andrae U, Balmaseda MA, Balsamo G, Bauer P, Bechtold P, Beljaars ACM, van de Berg L, Bidlot J, Bormann N, Delsol C, Dragani R, Fuentes M, Geer AJ, Haimberger L, Healy SB, Hersbach H, Hólm EV, Isaksen L, Kållberg P, Köhler M, Matricardi M, McNally AP, Monge-Sanz BM, Morcrette JJ, Park BK, Peubey C, de Rosnay P, Tavolato C, Thépaut JN, Vitart F (2011)
The ERA-interim reanalysis: configuration and performance of the data assimilation system. Q J R Meteorol Soc 137:553-597. https://doi.org/10.1002/qj.828

Di Capua G, Kretschmer M, Donner RV, van den Hurk B, Vellore R, Krishnan R, Coumou D (2020) Tropical and mid-latitude teleconnections interacting with the Indian summer monsoon rainfall: a theory-guided causal effect network approach. Earth System Dyn 11:17-34. https://doi.org/10.5194/esd-11-17-2020

Dimri AP (2004) Impact of horizontal model resolution and orography on the simulation of a western disturbance and its associated precipitation. Meteorol Appl 11:115-127

Ding Q, Wang B (2005) Circumglobal teleconnection in the northern hemisphere summer. J Clim 18:3483-3505. https://doi.org/10. 1175/jcli3473.1

Farinotti D, Immerzeel WW, de Kok RJ, Quincey DJ, Dehecq A (2020) Manifestations and mechanisms of the Karakoram glacier anomaly. Nat Geosci 13:8-16. https://doi.org/10.1038/ s41561-019-0513-5

Feng X-Y, Liu C-H, Rasmussen R, Fan G-Z (2014) A 10-yr climatology of Tibetan Plateau vortices with NCEP climate forecast system reanalysis. J Appl Meteorol Climatol 53:34-46

Ferrel W (1856) An essay on the winds and currents of ocean. Nashv J Med Surg 11:287-201

Forsythe N, Kilsby CG, Fowler HJ, Archer DR (2012) Assessment of runoff sensitivity in the Upper Indus Basin to interannual climate variability and potential change using MODIS satellite data products. Mt Res Dev 32:16-30

Forsythe N, Fowler HJ, Li X-F, Blenkinsop S, Pritchard D (2017) Karakoram temperature and glacial melt driven by regional atmospheric circulation variability. Nat Clim Change 7:664670. https://doi.org/10.1038/NCLIMATE3361

Fowler HJ, Archer DR (2006) Conflicting signals of climatic change in the Upper Indus Basin. J Clim 19:4276-4293. https://doi.org/ $10.1175 /$ jcli3860.1

Gardelle J, Berthier E, Arnaud Y (2012) Slight mass gain of Karakoram glaciers in the early twenty-first century. Nat Geosci 5:322

Gill AE (1980) Some simple solutions for heat-induced tropical circulation. Q J R Meteorol Soc 106:447-462

Hadley G (1735) VI. Concerning the cause of the general tradewinds. Philos Trans R Soc Lond 39:58-62

Halley E (1687) An historical account of the trade winds, and monsoons, observable in the seas between and near the Tropicks, with an attempt to assign the physical cause of the said winds. Philos Trans R Soc Lond 16:153-168. https://doi.org/10.1098/ rstl.1686.0026

Hasson S, Böhner J, Lucarini V (2017) Prevailing climatic trends and runoff response from Hindukush-Karakoram-Himalaya. Earth Syst Dyn 8:337-355. https://doi.org/10.5194/esd-8-337-2017

Hewitt K (2005) The Karakoram anomaly? Glacier expansion and the 'elevation effect', Karakoram Himalaya. Mt Res Dev 25:332-340

Holton JR (2004) An introduction to dynamic meteorology, vol 88, 4th edn. Elsevier Academic Press, Amsterdam

Hunt KMR, Turner AG, Shaffrey LC (2017) The evolution, seasonality, and impacts of Western disturbances. Q J R Meteorol Soc 144:278-290. https://doi.org/10.1002/qj.3200

Hunt KMR, Curio J, Turner AG, Schiemann R (2018) Subtropical westerly jet influence on occurrence of western disturbances and Tibetan Plateau Vortices. Geophys Res Lett 45:8629-8636. https://doi.org/10.1029/2018gl077734

Jacob T, Wahr J, Pfeffer WT, Swenson S (2012) Recent contributions of glaciers and ice caps to sea level rise. Nature 482:514-518

Jiang Q, Li W, Fan Z, He X, Sun W, Chen S, Wen J, Gao J, Wang J (2021) Evaluation of the ERA5 reanalysis precipitation dataset over Chinese Mainland. J Hydrol 595:125660. https://doi.org/10. 1016/j.jhydrol.2020.125660 
Jin F, Hoskins BJ (1995) The Direct response to tropical heating in a baroclinic atmosphere. J Atmos Sci 52:307-319. https://doi.org/ 10.1175/1520-0469(1995)052\%3c0307:Tdrtth\%3e2.0.Co;2

Kääb A, Berthier E, Nuth C, Gardelle J, Arnaud Y (2012) Contrasting patterns of early twenty-first-century glacier mass change in the Himalayas. Nature 488:495-498

Khattak M, Babel M, Sharif M (2011) Hydro-meteorological trends in the upper Indus River basin in Pakistan. Clim Res 46:103-119. https://doi.org/10.3354/cr00957

Krishnan R, Kumar V, Sugi M, Yoshimura J (2009) Internal feedbacks from monsoon-midlatitude interactions during droughts in the Indian summer monsoon. J Atmos Sci 66:553-578. https://doi. org/10.1175/2008jas2723.1

Lau K, Yang S (2003) Walker circulation. In: Holton JR, Pyle JA, Curry A (eds) Encyclopedia of atmospheric sciences. Academic Press, pp 2505-2509

Li X-F, Yu J, Li Y (2013a) Recent summer rainfall increase and surface cooling over Northern Australia since the late 1970s: a response to warming in the tropical Western Pacific. J Clim 26:7221-7239. https://doi.org/10.1175/JCLI-D-12-00786.1

Li Z-L, Tang B-H, Wu H, Ren H, Yan G, Wan Z, Trigo IF, Sobrino JA (2013b) Satellite-derived land surface temperature: current status and perspectives. Remote Sens Environ 131:14-37

Li X-F, Fowler HJ, Forsythe N, Blenkinsop S, Pritchard D (2018) The Karakoram/Western Tibetan vortex: seasonal and year-to-year variability. Clim Dyn 52:3883-3906. https://doi.org/10.1007/ s00382-018-4118-2

Li X-F, Fowler HJ, Yu J, Forsythe N, Blenkinsop S, Pritchard D (2019) Thermodynamic controls of the western Tibetan vortex on Tibetan air temperature. Clim Dyn 53:4267-4290. https://doi.org/10.1007/ s00382-019-04785-2

Mölg T, Maussion F, Collier E, Chiang JCH, Scherer D (2017) Prominent midlatitude circulation signature in high Asia's surface climate during monsoon. J Geophys Res Atmos 122:12702-12712. https://doi.org/10.1002/2017jd027414

Parker DJ, Thorpe AJ (1995) Conditional convective heating in a baroclinic atmosphere: a model of convective frontogenesis. J Atmos Sci 52:1699-1711. https://doi.org/10.1175/1520-0469(1995)052\% 3c1699:Cchiab\%3e2.0.Co;2

Pisharoty PR, Desai BN (1956) Western disturbances and Indian weather. Indian J Meteorol Geophys 7:333-338

Pratap B, Dobhal DP, Bhambri R, Mehta M, Tewari VC (2016) Four decades of glacier mass balance observations in the Indian Himalaya. Reg Environ Change 16:643-658

Ramanathan V, Saha KR (1972) Application of a primitive equation barotropic model to predict movement of "western disturbances." J Appl Meteorol 11:268-272

Saeed S, Miiller WA, Hagemann S, Jacob D (2011) Circumglobal wave train and the summer monsoon over northwestern India and Pakistan: the explicit role of the surface heat low. Clim Dyn 37:1045-1060

Sharif M, Archer DR, Fowler HJ, Forsythe N (2013) Trends in timing and magnitude of flow in the Upper Indus Basin. Hydrol Earth Syst Sci 17:1503-1516. https://doi.org/10.5194/ hess-17-1503-2013

Sobrino JA, Jiménez-Muñoz JC, Paolini L (2004) Land surface temperature retrieval from LANDSAT TM 5. Remote Sens Environ 90:434-440
Syed FS, Yoo JH, Körnich H, Kucharski F (2012) Extratropical influences on the inter-annual variability of South-Asian monsoon. Clim Dyn 38:1661-1674. https://doi.org/10.1007/ s00382-011-1059-4

Tao S-Y, Ding Y-H (1981) Observational evidence of the influence of the Qinghai-Xizang (Tibet) Plateau on the occurrence of heavy rain and severe convective storms in China. Bull Am Meteorol Soc 62:23-30

Thomson J (1892) XVII. Bakerian lecture-on the grand currents of atmospheric circulation. Philos Trans R Soc Lond (A) 183:653-684

Wan Z, Dozier J (1996) A generalized split-window algorithm for retrieving land-surface temperature from space. IEEE Trans Geosci Remote Sens 34:892-905

Wang Z, Wu G, Wu T, Yu R (2004) Simulation of Asian monsoon seasonal variations with climate model R42L9/LASG. Adv Atmos Sci 21:879-889

Wang Z, Yang S, Duan A, Hua W, Ullah K, Liu S (2018) Tibetan Plateau heating as a driver of monsoon rainfall variability in Pakistan. Clim Dyn 52:6121-6130. https://doi.org/10.1007/ s00382-018-4507-6

Wu G, Zhang Y (1998) Tibetan Plateau forcing and the timing of the monsoon onset over South Asia and the South China Sea. Mon Weather Rev 126:913-927. https://doi.org/10.1175/15200493(1998)126\%3c0913:Tpfatt\%3e2.0.Co;2

Wu T, Liu P, Wang Z, Liu Y, Yu R, Wu G (2003) The performance of atmospheric component model R42L9 of GOALS/LASG. Adv Atmos Sci 20:726-742

Wu G, Liu Y, Zhang Q, Duan A, Wang T, Wan R, Liu X, Li W, Wang Z, Liang X (2007) The influence of mechanical and thermal forcing by the Tibetan Plateau on Asian climate. J Hydrometeorol 8:770-789

Wu G, Duan A, Liu Y, Mao J, Ren R, Bao Q, He B, Liu B, Hu W (2015) Tibetan Plateau climate dynamics: recent research progress and outlook. Natl Sci Rev 2:100-116

Wu G, Liu Y (2000) Thermal adaptation, overshooting, dispersion, and subtropical anticyclone part I: thermal adaptation and overshooting. Scientia Atmospherica Sinica 4:433-446

Ye D-Z, Wu G-X (1998) The role of the heat source of the Tibetan Plateau in the general circulation. Meteorol Atmos Phys 67:181-198. https://doi.org/10.1007/BF01277509

Yeh T (1957) On the formation of quasi-geostrophic motion in the atmosphere. J Meteorol Soc Jpn Ser II 35:130-134. https://doi. org/10.2151/jmsj1923.35A.0_130

Zar JH (1984) Biostatistical analysis. Prentice Hall, Hoboken

Zhou Y, Li Z, Li J (2017) Slight glacier mass loss in the Karakoram region during the 1970 s to 2000 revealed by KH-9 images and SRTM DEM. J Glaciol 63:331-342

Zwiers FW, von Storch H (1995) taking serial correlation into account in tests of the mean. J Clim 8:336-351

Publisher's Note Springer Nature remains neutral with regard to jurisdictional claims in published maps and institutional affiliations. 